E-ISSN: 2663-3361

P-ISSN: 2663-3213

IJRHRM 2021; 3(2): 20-23

Received: 04-05-2021

Accepted: 10-06-2021

Jahnavi Ravindra Bodhe

Department of Professional

Studies, Christ (Deemed to be university), Bangalore,

Karnataka, India
Corresponding Author: Jahnavi Ravindra Bodhe Department of Professional Studies, Christ (Deemed to be university), Bangalore, Karnataka, India

\section{Gamification of personality tests for recruitment}

\author{
Jahnavi Ravindra Bodhe
}

DOI: https://doi.org/10.33545/26633213.2021.v3.i2a.66

\begin{abstract}
Personality tests are widely used by organizations to recruit employees for different job positions. Candidates attempting a traditional personality test with a known questionnaire have an advantage to meet the employer requirements which can be misleading and it can mask the true personality of the prospective employee. The paper outlines the meaning of traditional personality tests and the concept of gamification. This paper analyses the use of gamified personality tests for recruiting employees by using different game types for detecting personalities.
\end{abstract}

Keywords: Gamification elements, personality tests, myers-briggs type indicator, big five model, personality traits, gamified elements.

\section{Introduction}

Contemporary organizations have various tests to recruit candidates for different job positions. Personality tests are one of the tests used for recruitment. These personality tests are used in hiring candidates for various jobs in an organization. Some companies require candidates of a particular personality for certain job roles. It is very easy for prospective employees to attempt these personality tests with a known questionnaire. This gives them an advantage to align their answers according to the employer's requirements. This defies the whole purpose of having a personality test because by doing this, the true personality of the candidate is masked. This can affect the company in many ways when they assign jobs to employees. To overcome this issue, personality detection through games is a genuine way to determine a candidate's personality. This process can happen through integrating traditional personality tests into Gamification. But before going in depth, let us learn about what these personality tests are and what Gamification is.

\section{Materials and Methods \\ 2.1 Personality Tests}

Personality traits are a set of characteristics and tendencies that determine people. The character of that individual occurring in different situations describes the personality trait of that individual. The "Myers-Briggs Type Indicator" and "the Big Five Model," are state of the art methods for quantifying and classifying traits of different personality types. MBTI is a 100-question personality test that asks people how they usually feel or act in particular situations. It classifies people based on how they prefer to focus their attention, col-let information, process and evaluate information, and orient themselves to the outer world. These classifications are then combined into 16 personality types.

The second most widely accepted model of personality is the five models of personality which is typically called the "Big Five". The five basic personality dimensions include most of the significant variations in human personality. The Big Five has found important relationships between these personality dimensions and job performance. As discussed, using these personality tests, we can clearly indicate the personality of a candidate which can help assign suitable job roles.

Traditional personality tests like MBTI and Big5 help employers determine a potential fit. The Big Five personality test is a questionnaire that comprises questions regarding an individual's preferences and style. When it comes to the Big Five model, the traits employers look for is conscientiousness (dependable, persevering, and orderly). The second most favorable trait is agreeableness (those who are cooperative, tolerant, and flexible). Personality traits can vary depending on the job in question. Because of the flexibility offered by the test itself (measuring individuals on a scale instead of matching them definitively with one trait or the other), the Big Five Personality Test is one of the more dependable models when it comes to predicting job fit and performance. 
The Myers-Briggs consists of 93 questions with only two options to choose from. There are sixteen types of personalities that can result from combinations of the given categories. This test is a good indicator of how a candidate will work in a group. Clearly the question about candidates attempting the traditional personality test with a known questionnaire beforehand, which helps them meet the employer requirements still remains. Thus gasifying traditional personality tests is the best way for recruiting employees for various jobs and different positions in the organization hierarchy. But, let us first understand the concept of Gamification.

\subsection{Gamification}

Gamification is defined as a set of activities and processes to solve problems by using or applying the characteristics of game elements.. Many companies have experimented with adding games as part of their hiring process to give candidates an opportunity to prove their mettle. Gamification is becoming an essential part of the hiring process where performance is a concern, and thus, enabling the designers of gamified products to improve the performance of their games which could be of great value to the hiring process. The whole concept of Gamification in the workplace (applying game elements to business processes) isn't new although many predict that gamified strategies for hiring would fail. Some companies today use their own gamified elements to recruit and some stick to the traditional personality tests. However, by comparing MBTI and Big Five personality tests can help understand which method is the most effective in hiring.

Gamification in recruiting doesn't refer to one single type of game. Using puzzles, riddles and simulation assessments give job seekers scenarios that help recruiters evaluate how candidates react to different situations. There are many advantages like candidates who complete the game are clearly the most motivated, they can more easily evaluate people without much experience, they can also evaluate people who have diverse experience and can engage candidates. Games help build diverse teams with different personality types and can help reduce time in hiring. Detecting a person's personality through interactive puzzles, riddles, quizzes and simulation assessments can avoid prepared answers by job seekers and also help recruiters evaluate candidates accurately.

\subsection{Model for gamification for personality tests}

There have been various studies related to personality based Gamification for recruiting. Gamification can be used to know the effectiveness of an employee at a particular job. Gamification can also be used to detect personality types. For example, the candidates of introverted and extroverted are judged on their perception about the playfulness or the enjoyment of various Gamification elements which will help to know what ways candidates would like to work. Each personality would respond positively or negatively with certain Gamification elements. In the given example particularly, extrovert candidates would have positive responses towards more Gamification elements such as progress bars and leader boards whereas introvert candidates enjoy using fewer Gamification elements.

With the proposed recruiting model, the job seeker's personalities by using Gamification elements can help to create specific job types and job positions. In particular, this model applies the Gamification elements, MBTI and Big5 can help increase employee's work output and motivation. The recruiting Model consists of three main stages:

- Pre-Play stage

- Gameplay stage

- Post-play stage

\subsection{MBTI in Gamification}

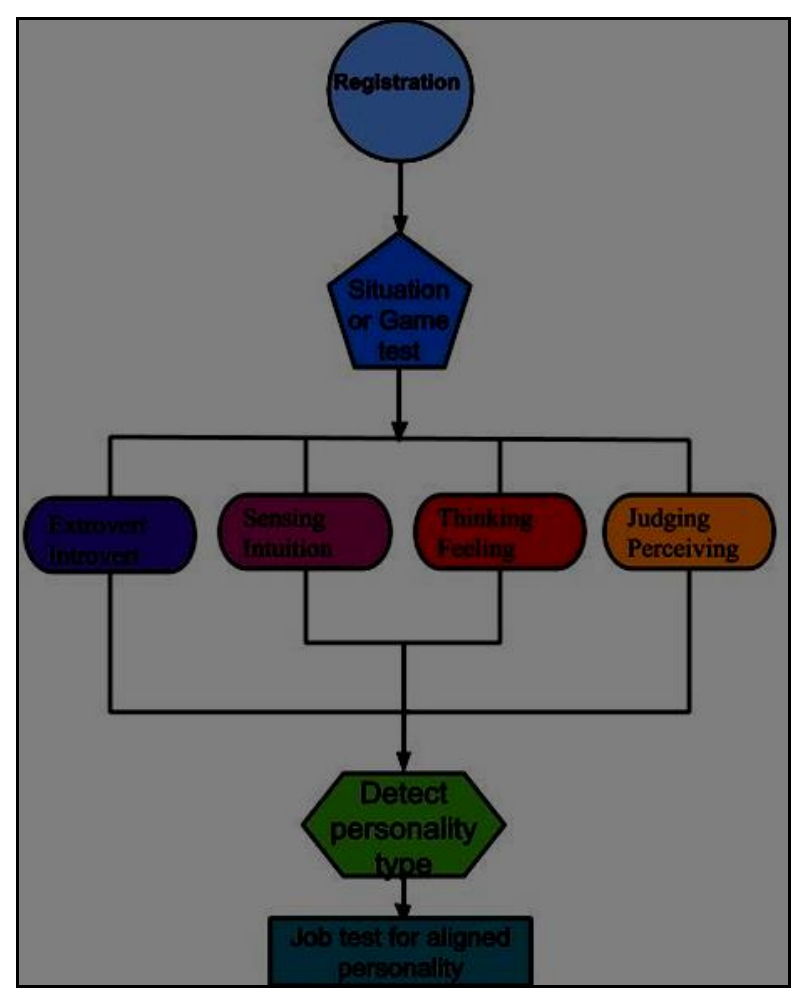

Fig 1: Recruiting Model 
Table 1: Representing game type for each MBTI personality

\begin{tabular}{|c|c|c|}
\hline Personality & Description & Games \\
\hline Extroverts & $\begin{array}{l}\text { They enjoy robust communication channels as they talk more, } \\
\text { Social play, Multiple objectives as they tend to multitask, They are } \\
\text { Quickly accessible as they are attuned to the external environment. }\end{array}$ & $\begin{array}{l}\text { - } \quad \text { Voice or face-to-face interaction games } \\
\text { - } \quad \text { Opportiplayer games (competitive or cooperative) } \\
\text { - } \quad \text { Quatar customization } \\
\end{array}$ \\
\hline Introverts & $\begin{array}{l}\text { They tend to have limited communication channels, Solo play as } \\
\text { they are comfortable to be alone, Focused objectives as they focus } \\
\text { on one thing at a time. }\end{array}$ & $\begin{array}{l}\text { Text chat games } \\
\text { - } \quad \text { Single-player games } \\
\quad \text { Story arcs/lore games }\end{array}$ \\
\hline Sensors & $\begin{array}{l}\text { They like limited choices, Managing data, Dealing with immediate } \\
\text { issues and admire practical solutions, Specific processes and have } \\
\text { slow progression toward objectives as they work at a steady pace. }\end{array}$ & $\begin{array}{l}\text { Few but meaningful choices } \\
\text { - } \quad \text { Resource management games } \\
\text { - } \quad \text { Gradual progression games }\end{array}$ \\
\hline Intuitive & $\begin{array}{l}\text { They like variety of choices as they admire creative ideas, Mystery } \\
\text { and discovery as the love noticing things that are new and different, } \\
\text { Customization of progression and like Irregular play sessions }\end{array}$ & $\begin{array}{l}\text { Open-ended or branching decisions } \\
\text { Plot-twists games with exploration } \\
\text { Progression along multiple paths games } \\
\text { long session games that are rewarding }\end{array}$ \\
\hline Thinkers & $\begin{array}{c}\text { They like mental challenges as they make decisions based on logic, } \\
\text { they are open to competition, fair as they value honesty and they } \\
\text { like status building and are motivated by achievement. }\end{array}$ & $\begin{array}{l}\text { Puzzles to solve } \\
\text { - } \quad \text { Puborts, contests, with Awards/badges } \\
\text { - Objective chains games }\end{array}$ \\
\hline Feelers & $\begin{array}{c}\text { They love social challenges as they are friendly and value people, } \\
\text { cooperative activities and diplomatic as they have a tactful } \\
\text { personality. }\end{array}$ & $\begin{array}{l}\text { - } \quad \text { Situation games to deal with/figure out } \\
\text { - } \quad \text { Negotiation } \\
\text { - } \quad \text { Political activities situations }\end{array}$ \\
\hline Judgers & $\begin{array}{c}\text { They like exercising control, they are completionists and have the } \\
\text { tendency to finish projects, love complexity, planning and decisions } \\
\text { and work towards a reward }\end{array}$ & $\begin{array}{l}\text { Numerous decisions making games } \\
\text { - } \quad \text { Timers and deadlines games } \\
\text { - } \quad \text { Unintuitive rule sets }\end{array}$ \\
\hline Perceivers & $\begin{array}{l}\text { They love freedom as they question the need for rules, unbound } \\
\text { play and try a bit of many things as they try keeping their options } \\
\text { open, they love simplicity, surprise/delight as they are spontaneous. }\end{array}$ & $\begin{array}{l}\text { - } \quad \text { Sandbox style play } \\
\text { - } \quad \text { Vo restrictions/penalty games } \\
\text { - } \quad \text { Unexpected events games } \\
\text { The games themselves should create enjoyment }\end{array}$ \\
\hline
\end{tabular}

\subsection{Big 5 in Gamification}

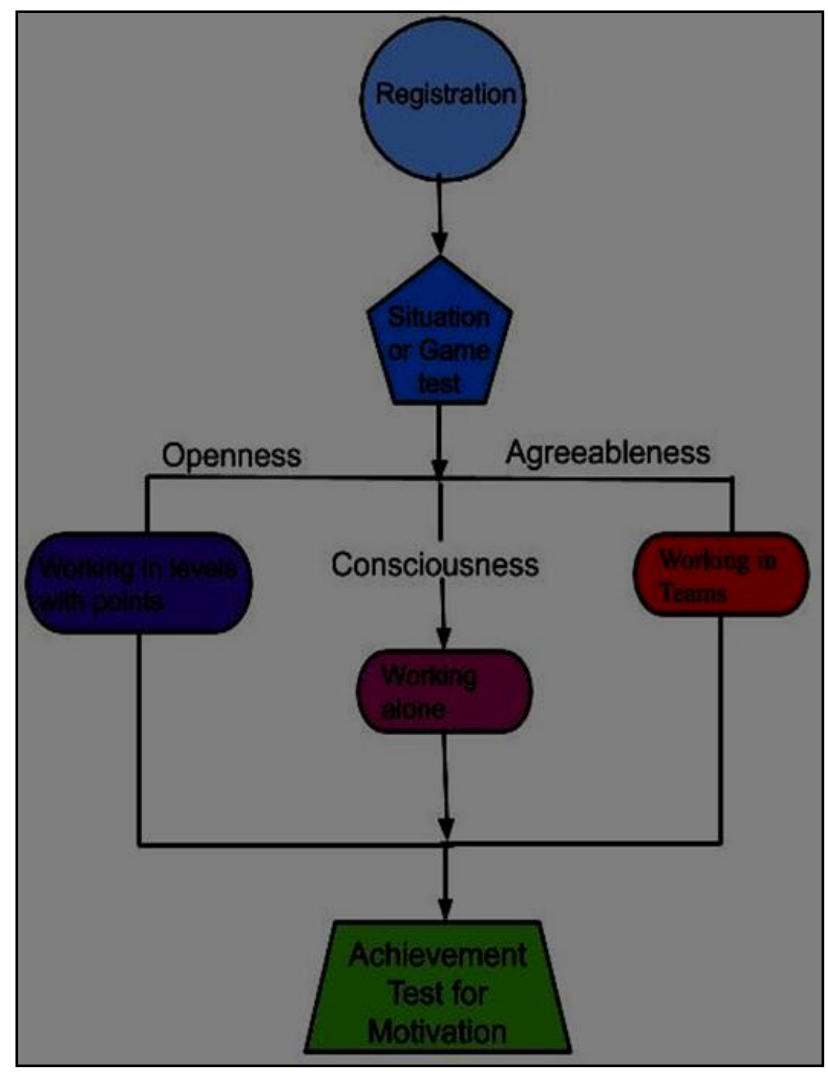

Fig 2: Recruiting Model 
Table 2: Representing game type for each Big5 personality

\begin{tabular}{|c|c|c|}
\hline Personality & Description & \\
\hline Openness & $\begin{array}{l}\text { Openness to experience refers to one's willingness to try new things as } \\
\text { well as engage in imaginative and intellectual activities. It includes the } \\
\text { ability to "think outside of the box." }\end{array}$ & \multirow{5}{*}{$\begin{array}{c}\text { Games with questions of visual elements/pictures } \\
\text { for detecting if user is visual and active } \\
\text { Practical tasks with strict information games for } \\
\text { sensing and intuition } \\
\text { Case studies with multiple step games if user is } \\
\text { active, sensing, visual and sequential } \\
\text { Responding positively for all Gamification } \\
\text { elements is correlated to all working styles show } \\
\text { extroversion } \\
\text { Responding negatively is correlated to all working } \\
\text { styles show neuroticism } \\
\text { These Games should include badges, leader } \\
\text { boards, points, levels, feedback, time track, stories } \\
\text { progress bar and competition }\end{array}$} \\
\hline Neuroticism & $\begin{array}{c}\text { The overall emotional stability of an individual through how they } \\
\text { perceive the world. It takes into account how likely a person is to } \\
\text { interpret events as threatening or difficult. }\end{array}$ & \\
\hline Conscientiousness & $\begin{array}{r}\text { Describes a person's ability to re } \\
\text { engage in goal- directed beha } \\
\text { control, inhibition, an }\end{array}$ & \\
\hline Agreeableness & $\begin{array}{r}\text { How people t } \\
\text { which consist } \\
\text { per }\end{array}$ & \\
\hline Extroversion & $\begin{array}{l}\text { Reflects the tendency and intensity to which someone seeks interaction } \\
\text { with their environment, particularly socially. It encompassed the } \\
\text { comfort and assertiveness levels of people in social situations. }\end{array}$ & \\
\hline
\end{tabular}

\section{Results and Discussion}

\subsection{Application of gamification by companies}

Many organizations use various gamification applications for recruiting employees. For example, Google organizes a Google Code Jam software-writing competition as a way to find fresh, new talent to work for the company. They use it as a way to attract potential hires with the right skills for the job and company. Marriott International to recruit newbies by using their own developed game called My Marriott Hotel which allows the candidates to run their own virtual hotel in which they design their own restaurant, purchase inventory, train employees and serve guests. It simulates the whole experience to run a hotel business where points are being awarded according to the customer service the players provide. They win points for every satisfied customer and they lose points for poor customer service. NTT uses an internal game called 'Samurai' to test leadership qualities where the participants join a quest to show how good they are at managing others. The game helps NTT to find good leaders within the company and gives insights on who needs more help in which area.

\section{Conclusion}

The traditional personality tests for the hiring process prevents recruiters from predicting which candidates will be successful. To know the prospective employee's personality without any discrepancies, using Gamification is the solution for it. Personality tests integrated with Gamification in recruitment is the suitable solution for engaging a diverse pool of candidates, which will help to pick out the finest applicants and on boarding them in an amusing way, all the while - allowing candidates to choose an employer as per their liking. Hence, we can say that using a personality gamification model in HR is a win-win solution for both employers and candidates.

\section{References}

1. Personality and its theories. (n.d.). Management Consulting Courses. https://managementconsultingcourses.com/Lesson31Per sonality\&ItsTheories.pdf

2. Nikoletta B. (N.D.). Gamification in recruiting: How and why to give it a shot. Workable. https://resources.workable.com/stories-andinsights/gamification-in-recruiting-effectiveness

3. Kaelyn B. (N.D.). The Most Common Employer Personality Tests: The Big Five, Myers-Briggs, and
More.

TCK

Publishing.

https://www.tckpublishing.com/employer-personalitytests/

4. Sara C. 9 examples of gamification in HR. HR Trend Institute 2019. https://hrtrendinstitute.com/2019/02/25/9-examples-ofgamification-in-hr/

5. Caitlin W. 5 Companies That Are Successfully Using Gamification for Recruiting. Linkedin 2015. https://business.linkedin.com/talent-

solutions/blog/recruiting-strategy/ 2015/5-companiesthat-are-successfully-using-gamification-for-recruiting

6. Charles B. A Framework for Evaluating the Effectiveness of Gamification Techniques by Personality Type. International Conference on HCI in Business 2014, 387-388. https://doi.org/10.1007/978-3319-07293-7_37

7. Lim A. The big five personality traits. Simply Psychology https://www.simplypsychology.org/big-fivepersonality.html 